\title{
OSTEOGENIC MEDIUM IS SUPERIOR TO GROWTH FACTORS IN DIFFERENTIATION OF HUMAN ADIPOSE STEM CELLS TOWARDS BONE- FORMING CELLS IN 3D CULTURE
}

\author{
L. Tirkkonen ${ }^{1,2,3}$, S. Haimi ${ }^{1,2,3,4, *}$, S. Huttunen ${ }^{1,2}$, J. Wolff ${ }^{1,2,5}$, E. Pirhonen ${ }^{6}$, G.K. Sándor ${ }^{1,2,3,7}$ and S. Miettinen ${ }^{1,2,3}$ \\ ${ }^{1}$ Adult Stem Cells, Institute of Biomedical Technology, University of Tampere, FI-33014 Tampere, Finland \\ ${ }^{2}$ BioMediTech, FI-33520 Tampere, Finland \\ ${ }^{3}$ Science Centre, Tampere University Hospital, FI-33521 Tampere, Finland \\ ${ }^{4}$ Department of Biomaterials Science and Technology, University of Twente, 7500 AE Enschede, The Netherlands \\ ${ }^{5}$ Oral and Maxillofacial Unit, Department of Otorhinolaryngology, Tampere University Hospital, \\ FI-33520 Tampere, Finland. \\ ${ }^{6}$ Onbone Oy, FI-00521 Helsinki, Finland \\ ${ }^{7}$ Department of Oral and Maxillofacial Surgery, Institute of Dentistry, University of Oulu, FI-90014 Oulu, Finland
}

\begin{abstract}
Human adipose stem cells (hASCs) have been recently used to treat bone defects in clinical practice. Yet there is a need for more optimal scaffolds and cost-effective approaches to induce osteogenic differentiation of hASCs. Therefore, we compared the efficiency of bone morphogenetic proteins (BMP-2 and BMP-7), vascular endothelial growth factor (VEGF), and osteogenic medium (OM) for the osteoinduction of hASCs in $3 \mathrm{D}$ culture. In addition, growth factors were tested in combination with OM. Commercially available bioactive glass scaffolds (BioRestore) and biphasic calcium phosphate granules (BoneCeramic) were evaluated as prospective carriers for hASCs. Both biomaterials supported hASC-viability, but BioRestore resulted in higher cell number than BoneCeramic, whereas BoneCeramic supported more significant collagen production. The most efficient osteo-induction was achieved with plain OM, promoting higher alkaline phosphatase activity and collagen production than growth factors. In fact, treatment with BMP-2 or VEGF did not increase osteogenic differentiation or cell number significantly more than maintenance medium with either biomaterial. Moreover, BMP-7 treatment consistently inhibited proliferation and osteogenic differentiation of hASCs. Interestingly, there was no benefit from growth factors added to OM. This is the first study to demonstrate that OM enhances hASCdifferentiation towards bone-forming cells significantly more than growth factors in $3 \mathrm{D}$ culture.
\end{abstract}

Keywords: Adipose stem cells; mesenchymal stem cells; bone tissue engineering; bioactive glass; biphasic calcium phosphate; growth factors; osteogenic differentiation; in vitro culture; 3D scaffolds.

*Address for correspondence:

Suvi Haimi

Department of Biomaterials Science and Technology

University of Twente

P.O. Box 217, 7500 AE Enschede, The Netherlands

Telephone Number: + 358401901771

E-mail: suvi.haimi@uta.fi
Introduction

Tissue engineered bone has emerged as a potential alternative to meet the increasing need for bone replacements in clinical medicine and to overcome the limitations of autologous grafts as well as the risks related to allogeneic bone grafts (Betz, 2002). Specifically, bone regeneration via autologous stem cell transplantation is a promising approach to treat large bone defects. For example, patient's own multipotent mesenchymal stem cells (MSCs) can be isolated from adipose tissue, expanded ex vivo, and transplanted to the defect site using biomaterial scaffold as a carrier (Mesimaki et al., 2009; Thesleff et al., 2011). Among adult stem cells, human adipose stem cells (hASCs) are readily available multipotent cells having the potential to differentiate into lineages of mesenchymal tissues, including bone, cartilage, fat, tendon, muscle, and marrow stroma (Zuk et al., 2001; Zuk et al., 2002; Park et al., 2010; Choi et al., 2012). The osteogenic capacity of ASCs has been demonstrated in both in vitro (Zuk et al., 2002; De Girolamo et al., 2007) and in vivo studies (Cowan et al., 2004; Hicok et al., 2004; Hattori et al., 2006; Di Bella et al., 2008; Behr et al., 2011). In addition, our group has reported several clinical cases, where autologous hASCs combined with biomaterials have been used to repair cranio-maxillofacial defects (Mesimaki et al., 2009; Thesleff et al., 2011).

In order to enhance the bone formation capacity, a number of inducing factors have been tested in combination with biomaterials and cells. Based on the fact that bone formation is modulated by a number of osteogenic factors released from the bone and surrounding tissues during the repair process, recombinant bone morphogenetic protein (BMP)-2 and BMP-7 have been utilised in clinical applications in order to stimulate bone healing (Samartzis et al., 2005; Garrison et al., 2007; Clokie and Sandor, 2008). Similar to BMPs, vascular endothelial growth factor A (VEGF-A) has been used to promote angiogenesis and osteogenesis of MSCs in vitro (Behr et al., 2011; D'Alimonte et al., 2011) and in vivo (Roldan et al., 2010; Behr et al., 2011). However, critical views on the use of BMPs have been emerging lately due to their short half-lives, expensiveness and ineffectiveness (Garrison et al., 2007; Garrison et al., 2010; Zuk et al., 
Table 1. The compositions of different media used in the study.

\begin{tabular}{|c|c|c|}
\hline \multicolumn{2}{|r|}{ Medium } & Supplements \\
\hline & $\begin{array}{l}\text { Maintenance } \\
\text { medium (MM) }\end{array}$ & DMEM/F-12, $10 \%$ FBS, $1 \%$ L-glutamine, $1 \%$ antibiotics \\
\hline & $\begin{array}{l}\text { Osteogenic medium } \\
(\mathrm{OM})\end{array}$ & $\begin{array}{l}5 \mathrm{nM} \text { dexamethasone, } 250 \mu \mathrm{M} \text { L-ascorbic acid 2-phosphate, } 10 \mathrm{mM} \beta \text {-glycerophoshate } \\
\text { (Sigma-Aldrich, MO, USA) in MM }\end{array}$ \\
\hline \multirow{3}{*}{ م } & $\mathrm{MM}+\mathrm{BMP}-2$ & $50 \mathrm{ng} / \mathrm{mL}$ bone morphogenetic protein-2 (Genscript, NJ, USA) in MM \\
\hline & $\mathrm{MM}+\mathrm{BMP}-7$ & $100 \mathrm{ng} / \mathrm{mL}$ bone morphogenetic protein-7 (Sigma-Aldrich) in MM \\
\hline & $\mathrm{MM}+\mathrm{VEGF}$ & $20 \mathrm{ng} / \mathrm{mL}$ vascular endothelial growth factor (R\&D Systems Inc, MN, USA) in MM \\
\hline \multirow{3}{*}{$\underset{\sim}{=}$} & $\mathrm{OM}+\mathrm{BMP}-2$ & $50 \mathrm{ng} / \mathrm{mL}$ BMP-2 (Genscript, NJ, USA) in OM \\
\hline & $\mathrm{OM}+\mathrm{BMP}-7$ & 100 ng/mL BMP-7 (Sigma-Aldrich) in OM \\
\hline & $\mathrm{OM}+\mathrm{VEGF}$ & $20 \mathrm{ng} / \mathrm{mL}$ VEGF (R\&D Systems Inc, MN, USA) in OM \\
\hline
\end{tabular}

2011). The clinical use of growth factors has been hindered by the significantly large, and hence costly, doses needed in humans. Large doses of exogenous growth factors may cause unexpected physiological effects ranging from bone resorption (Giannoudis et al., 2007) to heterotopic ossification (Wysocki and Cohen, 2007; Axelrad et al., 2008). Hence, alternative methods for effective osteoinduction of MSCs are under investigation (Kim et al., 2003; Kim et al., 2005; McCullen et al., 2010; Tirkkonen et al., 2011).

For example, osteogenic medium (OM) supplemented with L-ascorbic acid 2-phosphate (AsA2-P), dexamethasone (Dex) and $\beta$-glycerophosphate ( $\beta$-GP) has been commonly used for the osteogenic differentiation of MSCs in vitro (Zuk et al., 2001; Ogawa et al., 2004; Giusta et al., 2010; Rada et al., 2011). The in vivo studies have also shown the advantage of OM-induction in ASC-based bone regeneration; significantly greater bone healing was detected with the OM-induced ASCs compared to the non-induced ASCs (Dudas et al., 2006; Yoon et al., 2007; Di Bella et al., 2008; Schubert et al., 2011). However, the osteo-induction efficiency of $\mathrm{OM}$ has not been systematically compared to BMP-2, BMP-7 and VEGF with hASCs in vivo or in vitro. Although in vivo studies are required in the future to demonstrate the utility of $\mathrm{OM}$ over growth factors, obtaining sufficient in vitro data is of fundamental importance before it is reasonable to initiate in vivo studies.

In addition to effective osteo-induction, suitable biomaterial carriers for supporting the hASC proliferation and differentiation are required for successful bone regeneration. Bioactive glass and biphasic calcium phosphate, both biomaterials currently used in craniomaxillofacial (Peltola et al., 2006; Peltola et al., 2008; Frenken et al., 2010; Clozza et al., 2012b) and orthopaedic surgery (Lindfors et al., 2010; Garrido et al., 2011), were compared as prospective carriers for hASCs in the current study. Synthetic bioceramics are among the most promising biomaterials for the use of bone tissue engineering largely due to their capacity to form bone-like apatite layers in contact with physiological fluids, a reaction which facilitates their strong bonding to bone (Hench, 1998; Kokubo et al., 2003). Furthermore, bioactive glass and calcium phosphate biomaterials are capable of promoting bone formation through the dissolution of $\mathrm{Ca}$ and $\mathrm{P}$ ions (Xynos et al., 2000; E et al., 2010). Essential characteristics for silicate bioactive glasses include high $\mathrm{Na}_{2} \mathrm{O}$ and $\mathrm{CaO}$ content, high $\mathrm{CaO} / \mathrm{P}_{2} \mathrm{O}_{5}$ ratio, and $\mathrm{SiO}$ content less than $60 \mathrm{~mol} \%$. Biphasic calcium phosphates, in turn, consist of varying ratios of hydroxyapatite (HA) and beta-tricalcium phosphate $(\beta$-TCP). With slowly resorbing HA and more soluble $\beta$-TCP, the ratio $60 / 40 \mathrm{wt} \%$ of $\mathrm{HA} / \beta$-TCP has been widely used as it offers controlled degradation and optimal osseous substitution (Frenken et al., 2010; Ghanaati et al., 2012).

While searching for an optimal approach to treat patients with adipose stem cells, the aim of the present study was to compare the efficiency of BMP-2, BMP-7, VEGF and OM for the osteogenic differentiation of hASCs in clinically relevant $3 \mathrm{D}$ environment. In addition, BMP-2, BMP-7 and VEGF were tested in combination with OM.

\section{Materials and Methods}

\section{Biomaterial characterisation and preparation}

Two commercially available biomaterials, Straumann ${ }^{\circledR}$ BoneCeramic granules (Straumann AG, Basel, Switzerland) and Inion BioRestore ${ }^{\mathrm{TM}}$ (Inion Oy, Tampere, Finland) bioactive glass scaffolds were compared as $3 \mathrm{D}$ carriers for hASCs in this study. The morphology and surface topography of both materials was examined using scanning electron microscopy (SEM; Philips XL-30; Philips, Eindhoven, The Netherlands). The biomaterial samples were air-dried and sputter coated with gold prior to analysis with SEM.

The fully synthetic, granular form Straumann ${ }^{\circledR}$ BoneCeramic composed of biphasic calcium phosphate with $60 \%$ hydroxyapatite (HA; $100 \%$ crystalline) and $40 \% \beta$-tricalcium phosphate $(\beta$-TCP) was used in this study. BoneCeramic has a porosity of $90 \%$, and a granule size between 0.5 and $1.0 \mathrm{~mm}$ with interconnected pores of $100-500 \mu \mathrm{m}$ in diameter. For cell culturing, $0.25 \mathrm{~g}$ aliquots of sterile BoneCeramic granules were transferred onto 24well plates (Nunc, Roskilde, Denmark) using an analytical balance that was placed inside a laminar hood. The granules were incubated in $1 \mathrm{~mL}$ of corresponding medium (Table 1) for $48 \mathrm{~h}$ prior to cell seeding. 
The Inion BioRestore ${ }^{\mathrm{TM}}$ bioactive glass scaffolds used in this study had a nominal composition of 11.1-12.0 $\mathrm{wt} \%$ $\mathrm{Na}_{2} \mathrm{O}, 15.0-17.1 \mathrm{wt} \% \mathrm{~K}_{2} \mathrm{O}, 2.8-3.3 \mathrm{wt} \% \mathrm{MgO}, 12.7-$ $15.2 \mathrm{wt} \% \mathrm{CaO}, 2.7-3.8 \mathrm{wt} \% \mathrm{P}_{2} \mathrm{O}_{5}, 1.0-1.4 \mathrm{wt} \% \mathrm{~B}_{2} \mathrm{O}_{3}, 0.0$ $0.6 \mathrm{wt} \% \mathrm{TiO}_{2}$ and $48.5-52 \mathrm{wt} \% \mathrm{SiO}_{2}$. The porous bioactive glass scaffolds were manufactured from fibres as described previously (Moimas et al., 2006). Briefly, bioactive glass fibres of $75 \mu \mathrm{m}$ diameter and $3 \mathrm{~mm}$ length were produced by melt spinning. The fibres were sintered under defined conditions to obtain desired structural and mechanical properties. Scaffolds with porosity of $70 \%$ and dimensions of $7 \times 7 \times 3 \mathrm{~mm}$ were used in this study.

Before cell seeding, the bioactive glass scaffolds were sterilised with $70 \%$ ethanol followed by several steps of washing with Dulbecco's phosphate-buffered saline (DPBS; Lonza Biowhittaker; Verviers, Belgium), and incubated in $1 \mathrm{~mL}$ of corresponding medium (Table 1) for $48 \mathrm{~h}$.

\section{Cell isolation, characterisation and culture}

Adipose tissue samples were acquired from surgical procedures in the Department of Plastic Surgery, Tampere University Hospital with the patients' written consent. The study was conducted in accordance with the Ethics Committee of the Pirkanmaa Hospital District, Tampere, Finland (R03058). The adipose tissue samples were obtained from 11 donors (mean age $50 \pm 14$ years).

The adipose tissue was manually chopped into small fragments and digested with collagenase type I $(1.5 \mathrm{mg} /$ $\mathrm{mL}$; Invitrogen/Life Technologies, Carlsbad, CA, USA) in a water bath at $37{ }^{\circ} \mathrm{C}$ for $60 \mathrm{~min}$, and the hASCs were isolated by centrifugation. Following isolation, the hASCs were expanded in $T 75 \mathrm{~cm}^{2}$ polystyrene flasks (Nunc) in maintenance medium (MM) consisting of Dulbecco's modified Eagle's medium: nutrient mixture F-12 (DMEM/F-12 1:1) (Invitrogen, Paisley, UK), $10 \%$ foetal bovine serum (PAA Laboratories, Pasching, Austria), $1 \%$ antibiotics (100 U/mL penicillin; $100 \mathrm{U} / \mathrm{mL}$ streptomycin; Lonza Biowhittaker, Basel, Switzerland) and $1 \%$ L-glutamine (GlutaMAX I; Invitrogen). After expansion hASCs were cryo-preserved in gas phase nitrogen in freezing solution consisting of $10 \%$ dimethyl sulphoxide (Hybri-Max; Sigma-Aldrich, St. Louis, MO, USA) in foetal bovine serum (PAA Laboratories, Pasching, Austria).

After primary cell culture (at passage 1-2) the hASCs were characterised by a fluorescent-activated cell sorter (FACSAria; BD Biosciences, Erembodegem, Belgium). Monoclonal antibodies against CD14-PE, CD19-PE, CD49d-PE, CD73-PE, CD90-APC, CD106-PE, (BD Biosciences); CD45-FITC (Miltenyi Biotech, Bergisch Gladbach, Germany); CD34-APC, HLA-ABC-PE, HLADR-PE (Immunotools, Friesoythe, Germany); and CD105PE (R\&D Systems, Minneapolis, MN, USA) were used. The analysis was performed on 10,000 cells per sample and unstained cell samples were used to compensate for the background autofluorescence levels.

The hASCs needed for the study were thawed and expanded in maintenance medium in $T 75 \mathrm{~cm}^{2}$ polystyrene flasks (Nunc). At passage 2-4, the hASCs were seeded onto
BoneCeramic granules at a density of $9.7 \times 10^{4}$ cells per well, and similarly to the BioRestore scaffolds at a density of $9.7 \times 10^{4}$ cells per scaffold, using a small volume $(50 \mu \mathrm{L})$ of MM. The cells were let to attach at $+37{ }^{\circ} \mathrm{C}$ for $3 \mathrm{~h}$ before adding $1 \mathrm{~mL}$ of corresponding medium (Table 1). Fresh medium was changed 3 times per week. During each medium change the growth factors were freshly added to the medium from frozen aliquots avoiding multiple freezethaw cycles in order to keep the growth factors active. The experiments were repeated 3-6 times using one donor cell line per each repeat.

In the first part of this study, recombinant human BMP2 (rhBMP-2; Genscript, Pisataway, NJ, USA), BMP-7 (rhBMP-7; Sigma-Aldrich), and VEGF-A (rhVEGF ${ }_{165}$; R\&D Systems) were added to MM and compared with osteogenic medium (OM). In the second part of the study, the growth factors were combined with OM. The compositions of the different media used in the study are described in Table 1. The concentrations of BMP-2 (Barr et al., 2010), BMP-7 (Shen et al., 2010) and VEGF (Behr et al., 2011) used in this study were based on literature.

\section{Cell viability}

Cell attachment and viability were evaluated qualitatively using Live/dead-staining probes (Molecular Probes/ Invitrogen, Eugene, OR, USA) at day 3, 7 and 14. The hASCs were incubated for $45 \mathrm{~min}$ at room temperature with a mixture of $0.5 \mu \mathrm{M}$ calcein acetoxymethyl ester (Molecular Probes) and $0.25 \mu \mathrm{M}$ ethidium homodimer-1 (Molecular Probes). Images of the viable cells (green fluorescence) and dead cells (red fluorescence) were obtained using an Olympus IX51 phase contrast microscope with fluorescence optics and Olympus DP30BW camera (Olympus, Tokyo, Japan).

\section{Cell number}

The cell number of the samples was studied at 3-, 7- and 14-day time points by determining the amount of total DNA by CyQUANT Cell Proliferation Assay Kit (CyQUANT; Molecular Probes) according to the manufacturer's protocol. CyQUANT GR dye expresses fluorescence when bound to cellular nucleic acids.

The cells were washed with DPBS and lysed with $500 \mu \mathrm{L}$ of $0.1 \%$ Triton-X 100 buffer (Sigma-Aldrich). The Triton cell lysates were frozen and stored at $-70{ }^{\circ} \mathrm{C}$ until analysis. After thawing three parallel $20 \mu \mathrm{L}$ samples of each cell lysate were pipetted on a 96-well plate (Nunc) and mixed with $180 \mu \mathrm{L}$ of working solution containing CyQUANT GR dye. Fluorescence was measured at $480 / 520 \mathrm{~nm}$ with a microplate reader (Victor 1420 Multilabel Counter; Wallac, Turku, Finland).

\section{Alkaline phosphatase activity}

Alkaline phosphatase (ALP) activity was analysed at 3-, 7- and 14-day time points. ALP cleaves phosphate groups from $p$-nitrophenol phosphates at $\mathrm{pH} 10.4$ liberating yellow-coloured $p$-nitrophenol and phosphate. The rate of $p$-nitrophenol formation is proportional to the catalytic concentration of ALP in the sample. The ALP activity was determined from the same Triton-X 100 cell lysates as the cell number. 
Table 2. Surface marker expression of undifferentiated hASCs at passage 1-2. The results are displayed as mean percentage of the surface marker expression $(n=11)$.

\begin{tabular}{llccc}
\hline Antigen & Surface protein & Mean & SD & Expression \\
\hline CD14 & serum lipopolysaccharide binding protein & 1.8 & 1.1 & negative \\
CD19 & B lymphocyte-lineage differentiation antigen & 0.8 & 0.7 & negative \\
CD34 & sialomucin-like adhesion molecule & 17.4 & 8.3 & moderate \\
CD45 & leukocyte common antigen & 1.4 & 1.1 & negative \\
CD49d & integrin a2, VLA-4 & 41.7 & 20.0 & moderate \\
CD73 & ecto-50-nucleotidase & 90.4 & 9.4 & positive \\
CD90 & Thy-1 (T cell surface glycoprotein) & 99.3 & 0.6 & positive \\
CD105 & SH-2, endoglin & 95.7 & 4.4 & positive \\
CD106 & VCAM-1 (vascular cell adhesion molecule) & 1.1 & 1.1 & negative \\
HLA-ABC & major histocompatibility class I antigens & 42.0 & 24.6 & moderate \\
HLA-DR & major histocompatibility class II antigens & 0.9 & 0.8 & negative \\
\hline
\end{tabular}

Three parallel $20 \mu \mathrm{L}$ samples were pipetted on a MicroAmp ${ }^{\mathrm{TM}}$ Optical 96-well plate (Applied Biosystems, CA, USA). The reaction was started by pipetting $90 \mu \mathrm{L}$ of working solution per well, containing $50 \%$ of alkaline buffer solution (2-amino-2-methyl propanol; $1.5 \mathrm{M}$; pH 10.3; Sigma-Aldrich) and $50 \%$ of stock substrate solution ( $p$-nitrophenol phosphate; Sigma-Aldrich) and incubated for $15 \mathrm{~min}$ at $37^{\circ} \mathrm{C}$. The reaction was stopped by adding $50 \mu \mathrm{L}$ of $\mathrm{NaOH}(1 \mathrm{M}$, Sigma-Aldrich) and the colour intensity was determined with a microplate reader (Victor 1420) at $405 \mathrm{~nm}$.

\section{Collagen assay}

The amount of collagen was determined at 7- and 14-day time points by Sircol Soluble Collagen Assay (Biocolor, Carrickfergus, Northern Ireland). The basis of the assay was binding of Sirius red dye to [Gly-X-Y] peptide sequence of mammalian collagen types I-V. Production of collagenous matrix was measured, as it was not possible to analyse mineralisation due to the calcium containing 3D-scaffolds.

For the measurement, acid-soluble collagen was extracted from the cultures by $0.5 \mathrm{M}$ acetic acid (Merck, Darmstadt, Germany) containing $0.1 \mathrm{mg} / \mathrm{mL}$ pepsin (Sigma-Aldrich) for $2 \mathrm{~h}$ at $4{ }^{\circ} \mathrm{C}$. The collagen content was determined from $100 \mu \mathrm{L}$ samples, with $1 \mathrm{~mL}$ of Sircol Dye reagent (Sirius Red in picric acid; Biocolor) added to each aliquot and incubated with gentle shaking for $30 \mathrm{~min}$. The samples were centrifuged at $12,000 \mathrm{rpm}$ for $10 \mathrm{~min}$, and the collagen-dye pellet was washed once to remove unbound dye with $750 \mu \mathrm{L}$ of ice-cold Acid-Salt Wash Reagent (acetic acid, sodium chloride and surfactants; Biocolor). After centrifugation, the supernatant was discarded and the collagen-bound dye was released by adding $250 \mu \mathrm{L}$ of Alkali Reagent (0.5 M sodium hydroxide; Biocolor). The dye intensity was measured from two parallel $100 \mu \mathrm{L}$ samples on a 96-well plate (Nunc) with a microplate reader (Victor 1420) at $540 \mathrm{~nm}$.

\section{Statistical analysis}

Statistical analyses were performed with SPSS version 19 (IBM, Armonk, NY, USA). Data were reported as mean and standard deviation (SD). The effects of different culture conditions on cell number, ALP activity, and collagen content were compared using a one-way analysis of variance (ANOVA) with Tukey post hoc test. The results were considered significant when $p<0.05$. The effect of culture duration was analysed using a Student's $t$-test for independent samples for collagen content (day 7 versus day 14), and one-way ANOVA for cell number and ALP activity for comparing 3-, 7- and 14-day time points. In the first part of this study growth factors were added to control medium and compared with $\mathrm{OM}$, the experiments for cell number and ALP activity were repeated using 6 donor lines $(n=6)$, and the analysis of collagen content was repeated with 3 donor lines $(n=3)$. In the second part, where growth factors were tested in combination with OM, all experiments were repeated using 3 donor lines $(n=3)$.

\section{Results}

\section{Scanning electron microscopy}

The scanning electron microscopy (SEM) images (Fig. 1) illustrated the macro structure (Fig. 1a,b) and surface roughness (Fig. 1e,f) of the biomaterials. Based on the SEM images a larger surface area may be expected for BioRestore that is composed of small sized fibres (Fig. 1, left side). Regarding surface topography, BoneCeramic exhibited more surface roughness than BioRestore (Fig. 1e,f). Overall, the SEM images confirmed the high porosity of both biomaterials. More detailed information on material characteristics of BioRestore scaffold has been provided previously (Haimi et al., 2009a).

\section{Flow cytometric surface marker expression analysis}

The flow cytometric analysis (Table 2) demonstrated that the hASCs used in this study expressed the surface markers CD73, CD90, CD105, and lacked the expression of the CD14, CD19, HLA-DR, the haematopoietic marker CD45, and the vascular cell adhesion molecule CD106. The expression of CD34, CD49d and HLA-ABC, was moderate. Overall, the surface marker analysis confirmed the mesenchymal origin of the cells in agreement with literature (Dominici et al., 2006; McIntosh et al., 2006; Lindroos et al., 2010). 

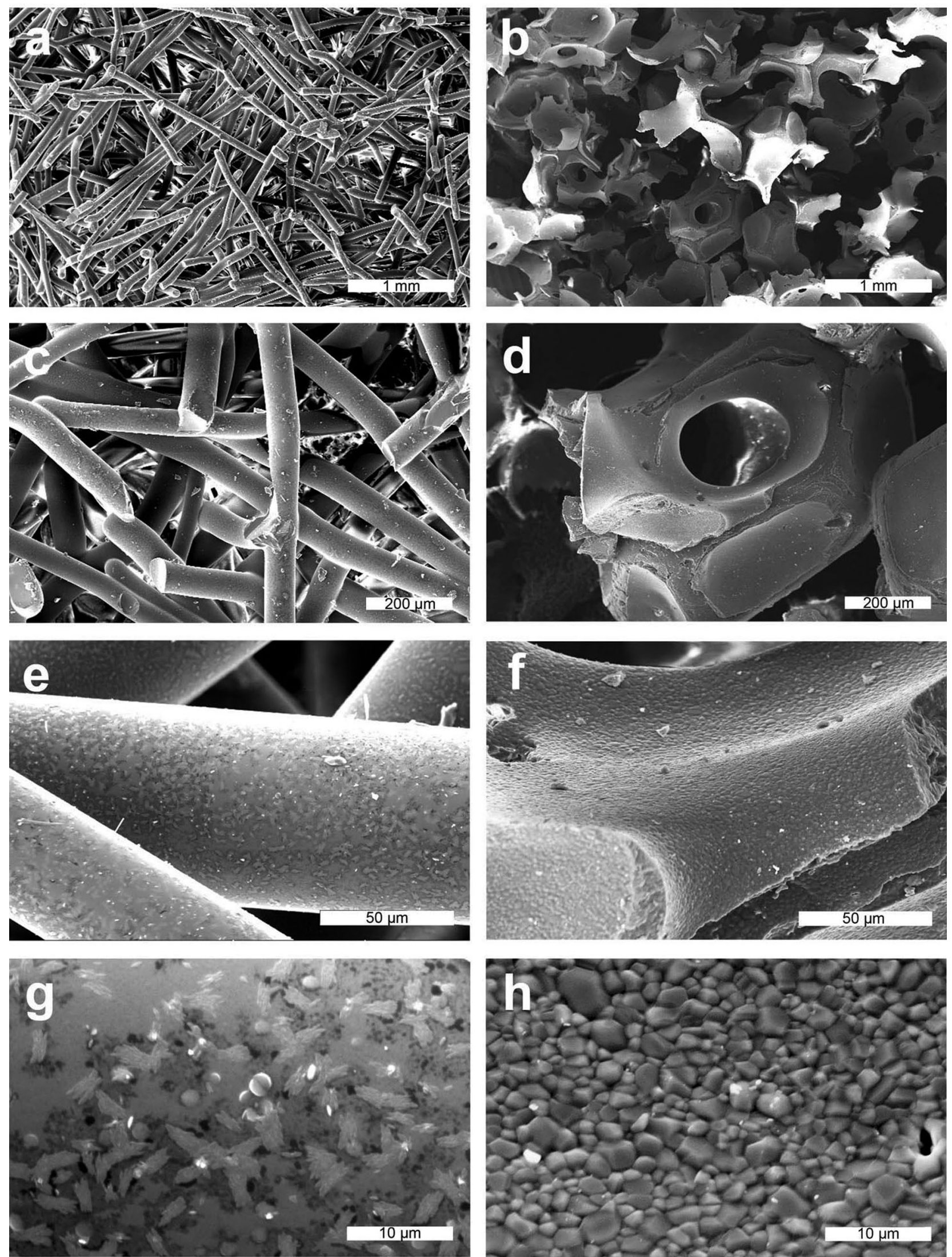

Fig. 1. Scanning electron micrographs of BioRestore (left; $\mathbf{a}, \mathbf{c}, \mathbf{e}, \mathbf{g}$ ) and BoneCeramic (right; $\mathbf{b}, \mathbf{d}, \mathbf{f}, \mathbf{h}$ ) at magnification of 20x (a, b), 80x (c, d), 500x (e, f), and 2000x ( $\mathbf{g}, \mathbf{h})$. Scale bars in the lower right corner of the micrographs. 

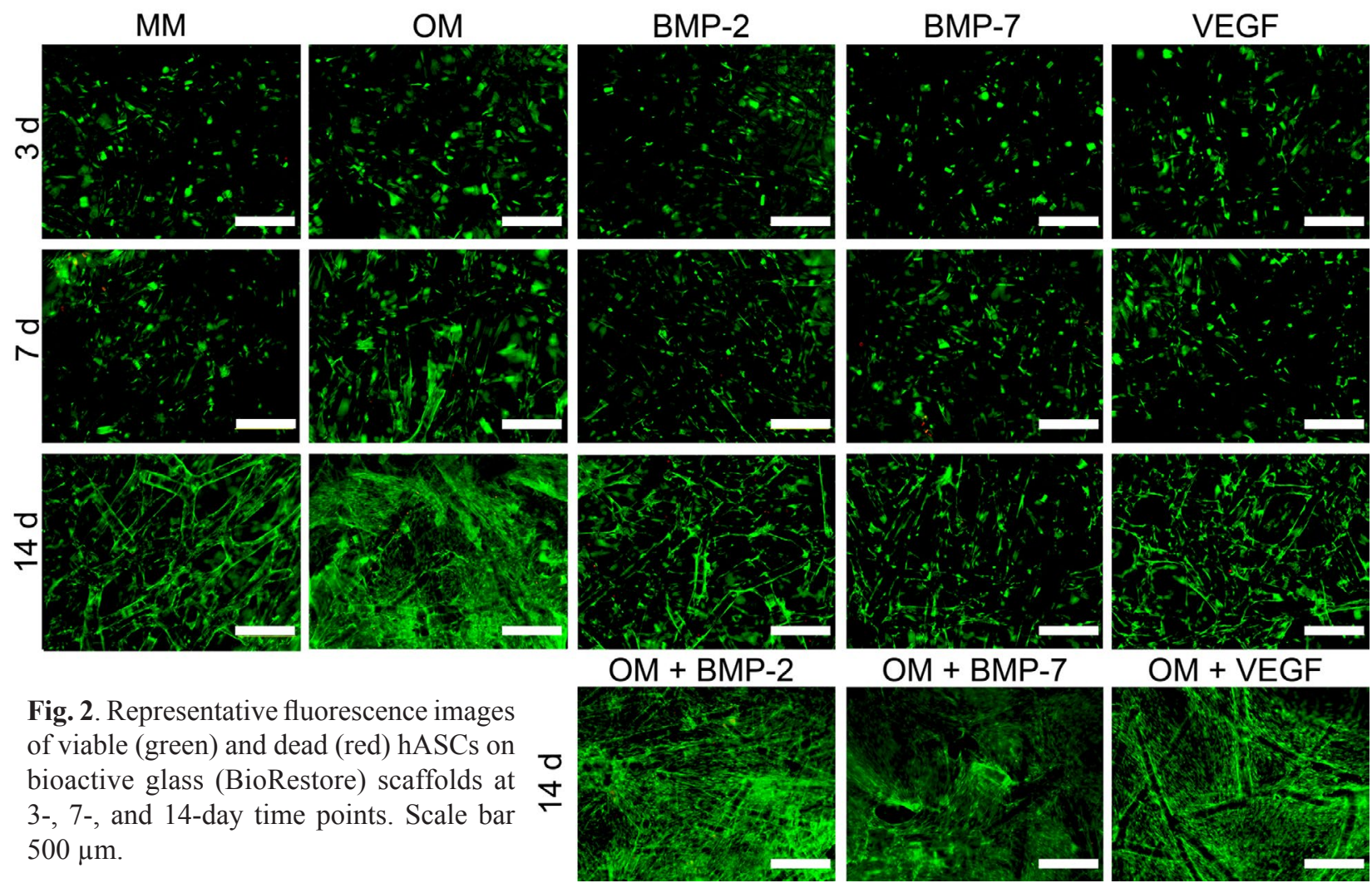

Fig. 2. Representative fluorescence images of viable (green) and dead (red) hASCs on bioactive glass (BioRestore) scaffolds at 3-, 7-, and 14-day time points. Scale bar $500 \mu \mathrm{m}$.
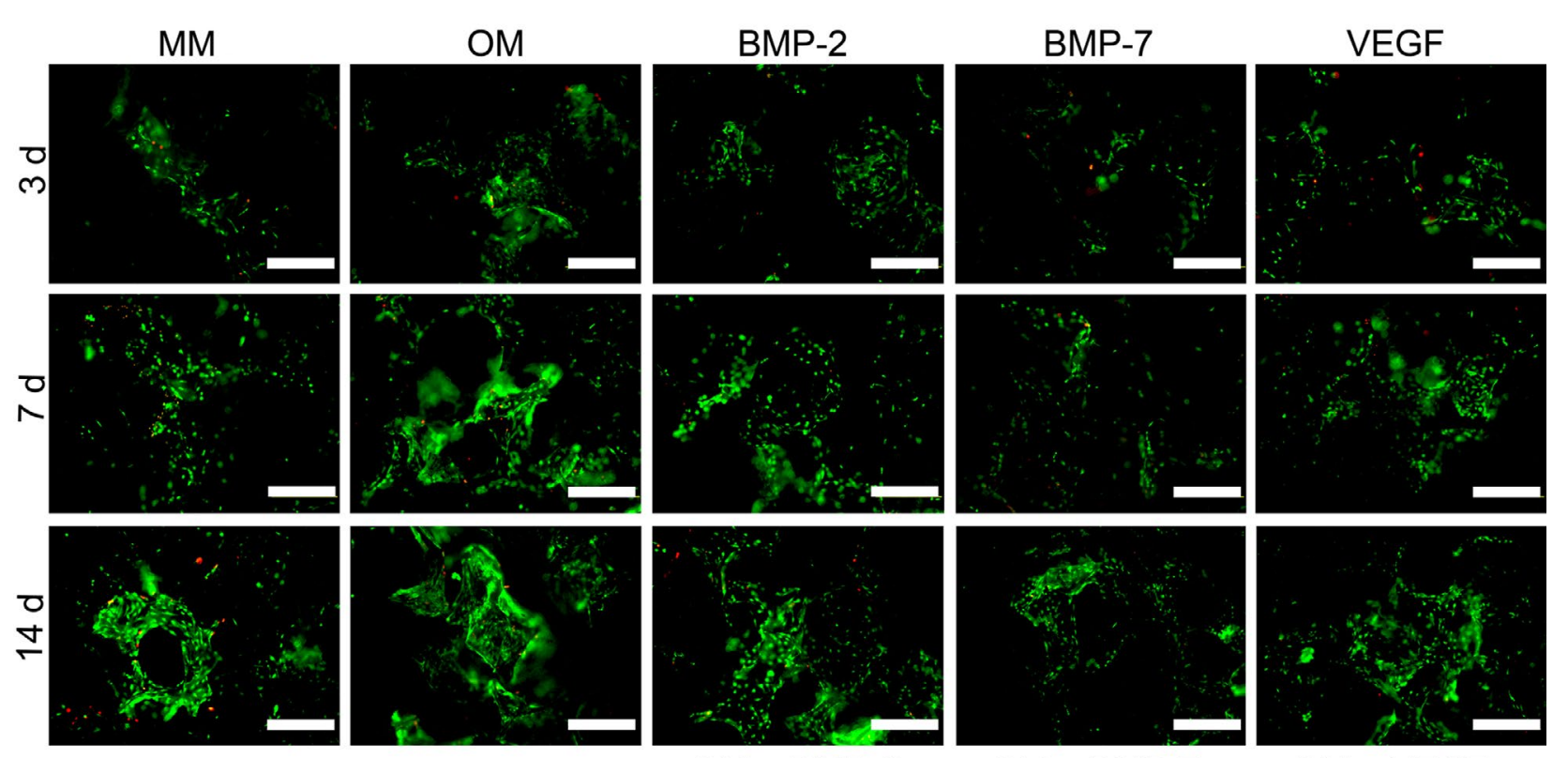

Fig. 3. Representative fluorescence images of viable (green) and dead (red) hASCs on 0 biphasic calcium phosphate (BoneCeramic) granules at 3-, 7-, and 14-day time points. Scale bar $500 \mu \mathrm{m}$.
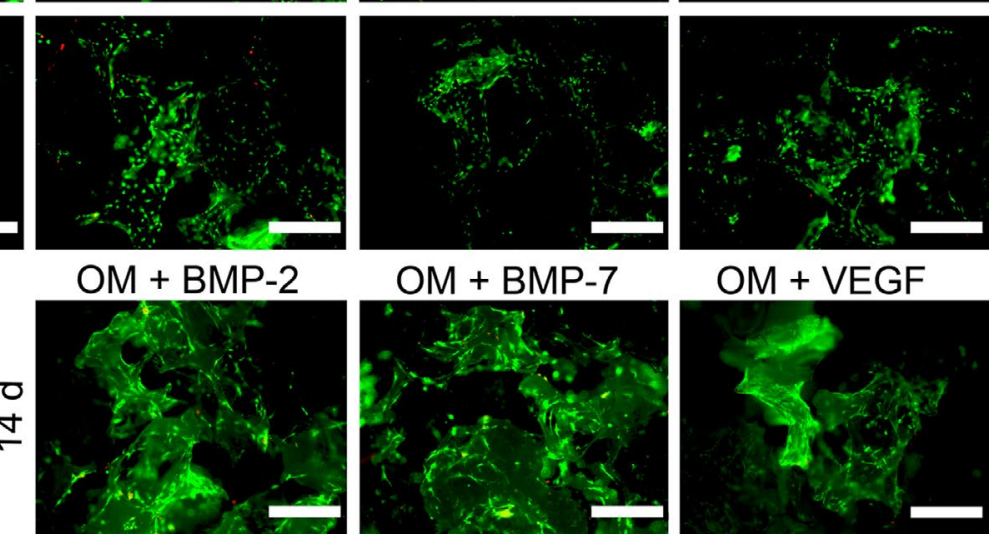

$\mathrm{OM}+\mathrm{VEGF}$

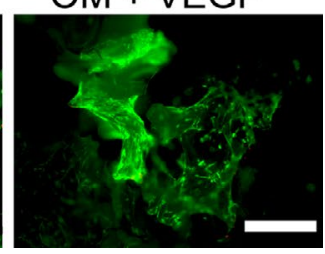

\section{Comparison of BioRestore and BoneCeramic} biomaterials

The hASCs seeded on both BioRestore (Fig. 2) and BoneCeramic (Fig. 3) were viable and proliferated steadily under control conditions during the whole 14-day culturing period as monitored by qualitative Live/dead Cell Viability (Fig. 2 and 3) and quantitative CyQuant Cell Proliferation
(Fig. 4) assays. According to Live/dead assay, BioRestore supported cell proliferation more than BoneCeramic. This was confirmed by the quantitative analysis of cell number (Fig. 4a), which showed 1.4-fold higher cell number with BioRestore than BoneCeramic in MM $(p=0.026)$, and 1.3-fold in OM $(p=0.002)$ at day 14 . 

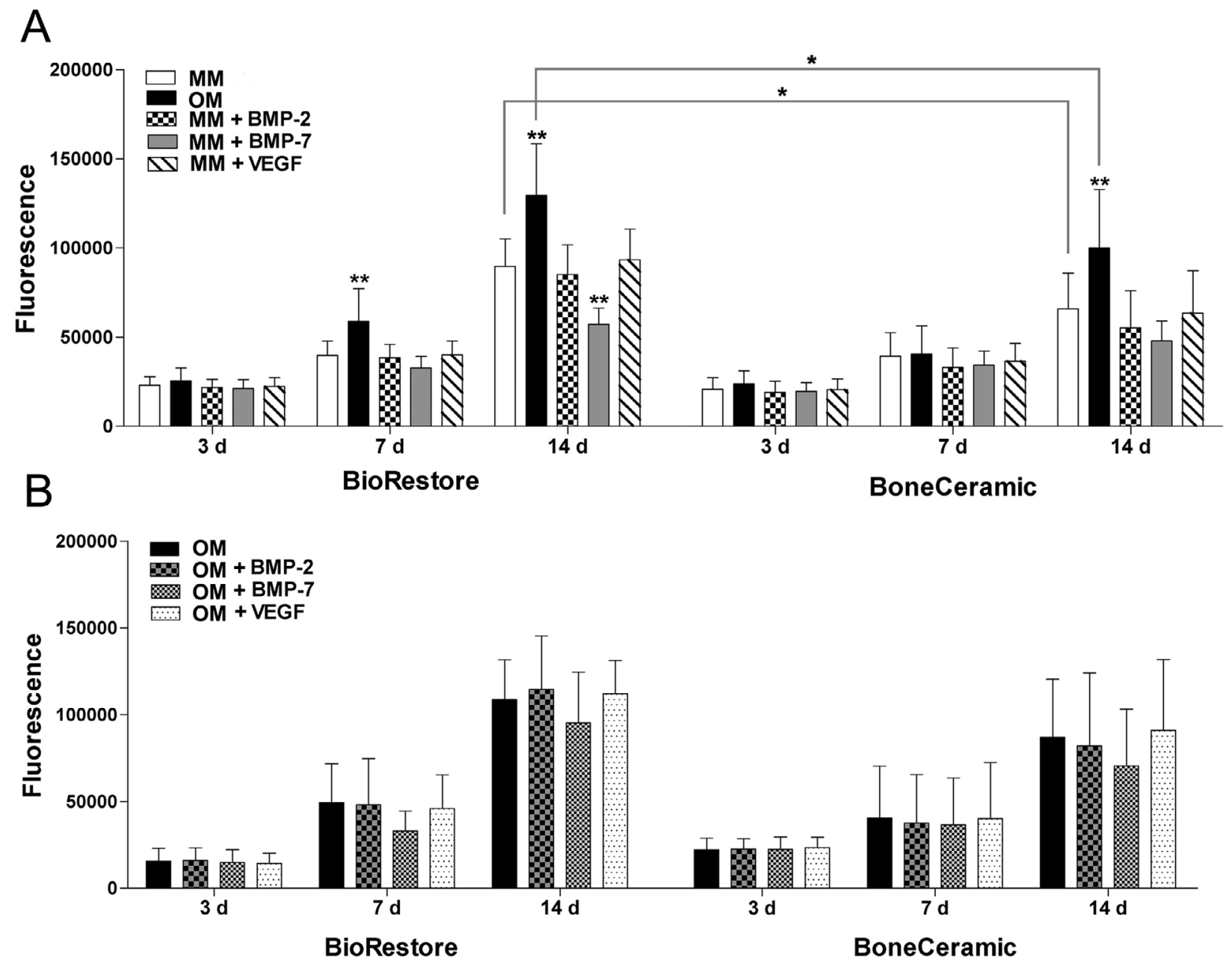

Fig. 4. Cell number at 3-, 7-, and 14-day time points on BioRestore or BoneCeramic. (A) Growth factors in MM: Number of hASCs cultured with MM, OM or growth factors in MM. * $p<0.05$ between the indicated groups. $* * p<0.05$ with respect to other groups within that time point. (B) Growth factors in OM: Number of hASCs cultured with OM or growth factors in OM. No significant differences in panel B. Results are expressed as mean fluorescence + SD.

The ALP activity of hASCs (Fig. 5) was supported equally by both biomaterials in MM, but the induction by OM was more significant and consistent in BoneCeramic. For example, with BoneCeramic the ALP activity was enhanced by OM 2-fold when compared to MM, 3-fold to BMP-2, 8-fold to BMP-7, and 2-fold to VEGF ( $p<0.05$ in all). In BioRestore, the ALP activity induced by OM was higher than with BMP-2 (1.7-fold) and BMP-7 (4.5-fold), but not when compared to MM.

Furthermore, BoneCeramic supported the collagen production of hASCs significantly more than BioRestore (Fig. 6a). Collagen production by hASCs grown on BoneCeramic in MM or MM + growth factors was significantly higher when compared to BioRestore both at day 7 and day 14. At day 14, the amount of collagen was 5-fold higher in BoneCeramic MM than in BioRestore MM $(p<0.05)$. In fact, BoneCeramic combined with MM produced comparable collagen levels to that made by osteo-induced hASCs grown on BioRestore. Induction by $\mathrm{OM}$ resulted in increased collagen production on both biomaterials at day 14 with the highest levels of collagen being produced by hASCs induced in OM on
BoneCeramic. However, the enhancement of collagen production was more intense in the case of BioRestore; OM resulted in 5 times more collagen than MM in BioRestore, but only a 1.9-fold induction in BoneCeramic - due to the high level of collagen present under control conditions. When compared to MM control, growth factor treatment did not increase collagen production on either biomaterial.

\section{Comparison of $\mathrm{OM}$ induction to $\mathrm{MM}$}

Overall, OM resulted in higher cell numbers and collagen production than MM with both biomaterials. When comparing the effect of $\mathrm{OM}$ to $\mathrm{MM}$ in BioRestore, a significant stimulation was detected on proliferation of hASCs (Fig. 4a). OM increased the cell number 1.5-fold on day 7 and 14 when compared to MM $(p<0.05)$. Live/dead analysis confirmed the high growth rate of OM-cultured hASCs in BioRestore (Fig. 2). In addition, OM induced significantly higher collagen production (5-fold) than MM at day 14 in BioRestore (Fig. 6a). In turn, the ALP activity of hASCs seeded in BioRestore was not significantly higher in OM than in MM (Fig. 5a). 

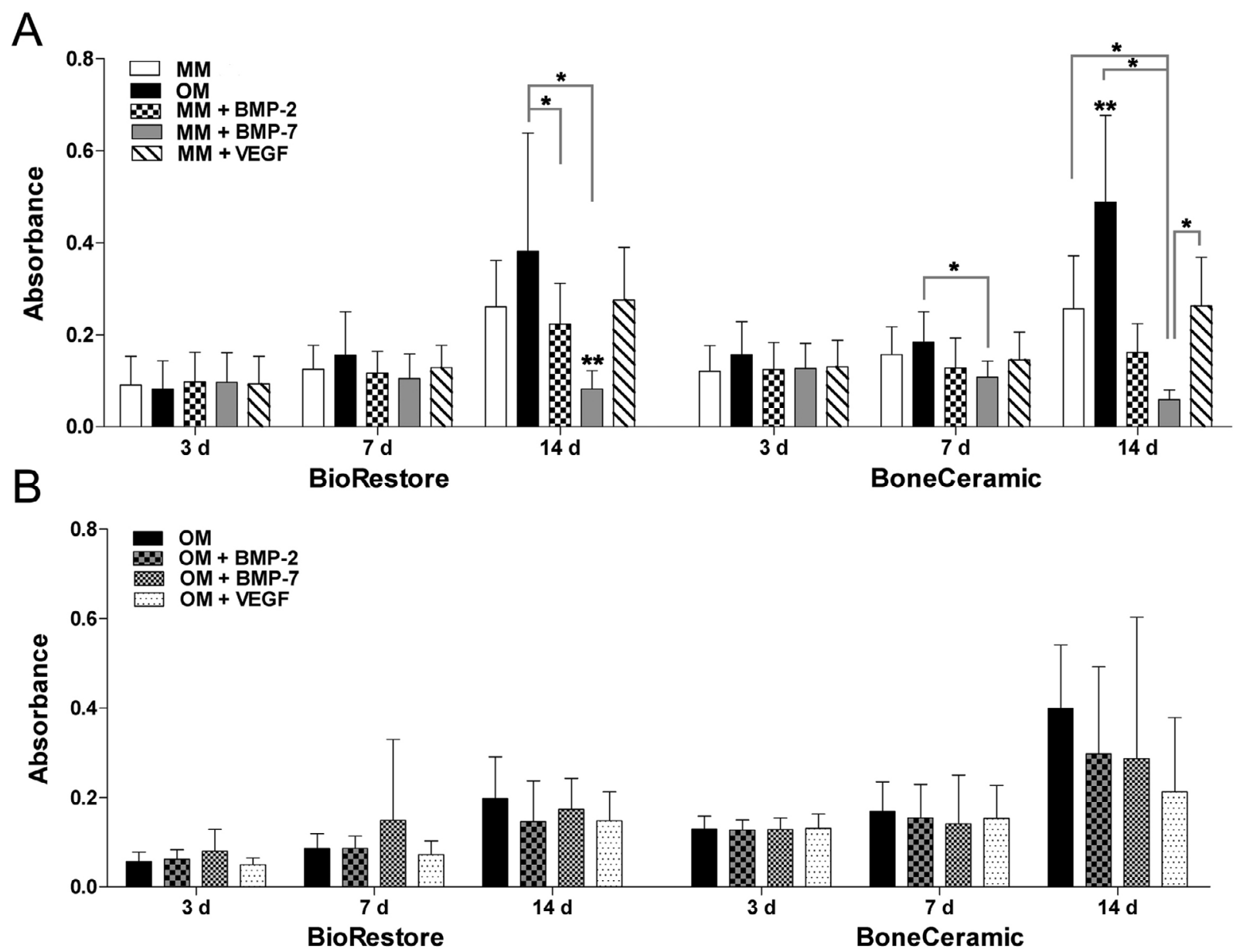

Fig. 5. ALP activity of hASCs at 3-, 7-, and 14-day time points on BioRestore or BoneCeramic. (A) Growth factors in MM: ALP activity of hASCs cultured with MM, OM or growth factors in MM. ${ }^{*} p<0.05$ between the indicated groups. ${ }^{* *} p<0.05$ with respect to other groups within that time point. (B) Growth factors in OM: ALP activity of hASCs cultured with OM or growth factors in OM. No significant differences in panel B. Results are expressed as mean absorbance $+\mathrm{SD}$.

In BoneCeramic, the cell number (Fig. 4a) was significantly higher in $\mathrm{OM}$ than in MM cultures (1.5fold) on day 14. In contrast, Live/dead analysis showed slightly higher cell number in OM than MM on day 7, but no notable difference between OM and MM on day 14 in BoneCeramic (Fig. 3). The ALP activity (Fig. 5a) and collagen production (Fig. 6a) were induced 1.9-fold more with OM than MM in BoneCeramic at day $14(p<0.05)$.

\section{Comparison of growth factor induction to $\mathrm{MM}$}

In general, all the growth factors tested in the present study supported the viability (Fig. 2 and 3) and proliferation of hASCs (Fig. 4a). BMP-2 and VEGF did not increase but rather supported similar levels of proliferation as MM (Fig. 4a). The result was similar with ALP activity (Fig. 5a) and collagen production (Fig. 6a), where BMP-2 and VEGF resulted in comparable levels as MM in both biomaterials. In contrast to BMP-2 and VEGF, BMP-7 resulted in two times lower cell number than $\mathrm{MM}$ in BioRestore $(p<0.001)$. Consistently, ALP activity (Fig. 5a) was three times lower in BMP-7 group than in MM in BioRestore $(p=0.002)$. Equally low amounts of collagen
(Fig. 6a) were produced by all growth factors and MM in hASCs cultured in BioRestore.

The effects of growth factors in BoneCeramic were mostly similar to BioRestore, i.e., no enhancement in comparison to MM. However, in BoneCeramic BMP-7 did not significantly inhibit proliferation. In turn, the adverse effect of BMP-7 was significant in ALP activity; four times lower values than with MM were detected on day 14 (Fig. 5a). Some differences in collagen production (Fig. 6a) were detected between the growth factor groups in BoneCeramic. On day 7, BMP-2 exhibited significantly higher collagen amount than MM and OM $(p<0.05)$, although there was no difference from MM on day 14 . Furthermore, VEGF exhibited significantly higher ALP activity and collagen content than BMP-7 (4.4-fold and 1.8-fold, respectively), but not higher in comparison to MM.

\section{Comparison of $\mathrm{OM}$ induction to growth factors}

Overall, OM showed superior capacity to induce osteogenic differentiation and proliferation of hASCs than the growth factors tested in the study. In BioRestore, 


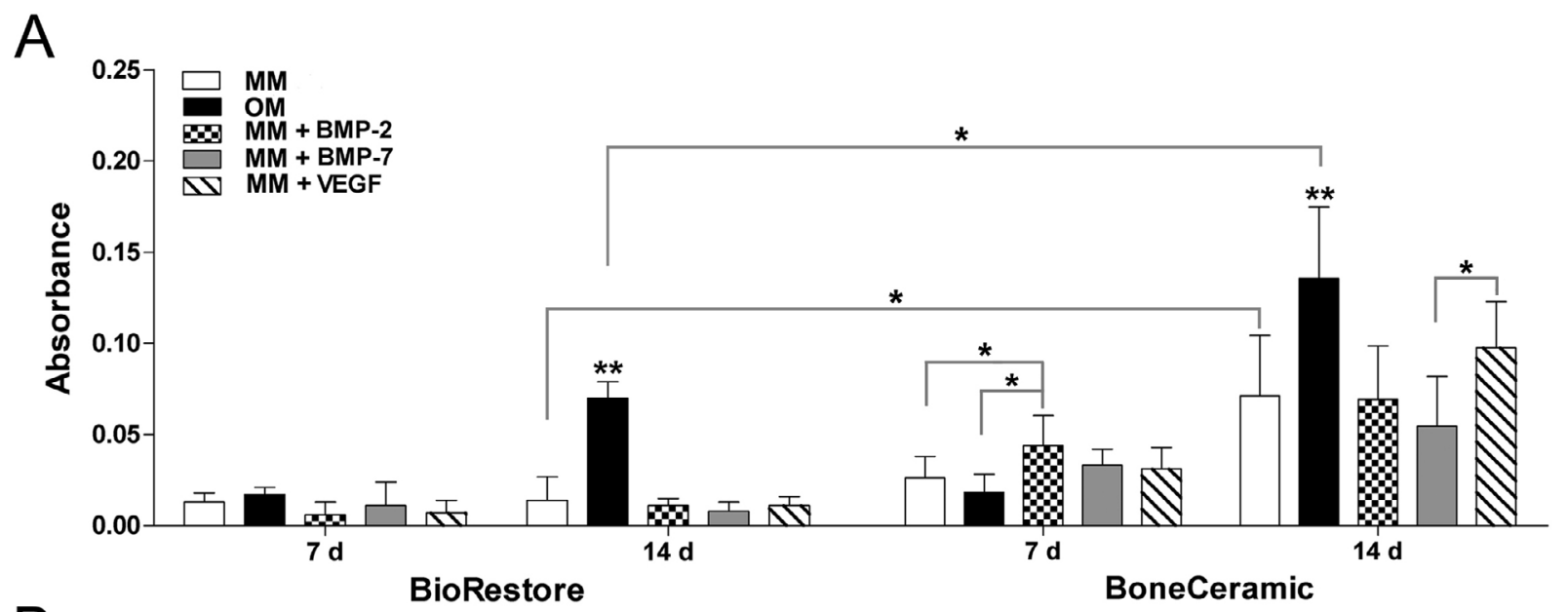

B

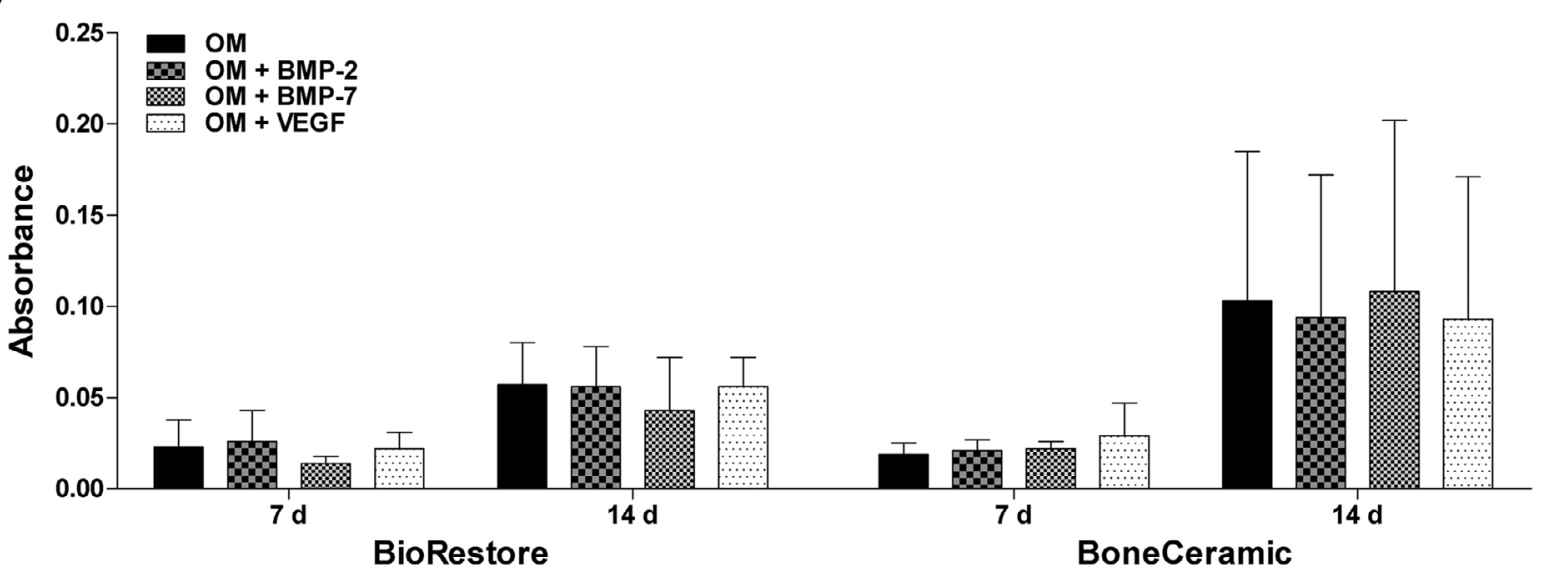

Fig. 6. Collagen production of hASCs at 7- and 14-day time points on BioRestore or BoneCeramic. (A) Growth factors in MM: Collagen production of hASCs cultured with MM, OM or growth factors in MM. * $p<0.05$ between the indicated groups. ${ }^{*} p p<0.05$ with respect to other groups within that time point. (B) Growth factors in OM: Collagen production of hASCs cultured with OM or growth factors in OM. No significant differences in panel B. Results are expressed as mean absorbance + SD.

Live/dead analysis (Fig. 2) showed increased viability and cell number by the OM group when compared with growth factor groups at day 7 and 14. This was confirmed by the quantitative analysis of cell numbers (Fig. 4a); OM induced significantly higher cell numbers than growth factors (1.4- to 2.2-fold) in BioRestore. In a similar way, the collagen production was enhanced 6- to 9-fold by OM when compared to growth factors in BioRestore (Fig. 6a). $\mathrm{OM}$ also induced significantly higher ALP activity than BMP-2 (1.7-fold) and BMP-7 (4.6-fold) in BioRestore (Fig. 5a). VEGF resulted in comparable level of ALP activity to $\mathrm{MM}$ and $\mathrm{OM}$ in BioRestore. The OM-induced ALP activity was donor dependent, and hence was not as consistent as the OM-induced collagen production.

In BoneCeramic, the growth factors supported comparable levels of viability to OM and MM (Fig. 3). However, according to the quantitative analysis of cell number (Fig. 4a), OM did result in significantly higher numbers of cells on day 14 than the growth factor groups $(p<0.05)$. The effect of OM on ALP activity (Fig. 5a) and collagen production (Fig. 6a) in BoneCeramic was significantly higher than with any of the growth factors.
In ALP activity, the effects of OM were 2- to 8-fold, and in collagen production 1.4- to 2.5-fold in comparison to growth factors. In particular, the negative effect of BMP-7 was evident in ALP activity of hASCs seeded on BoneCeramic (Fig. 5a), as the ALP activity of BMP-7 group decreased with time $(p=0.006$, day 7 versus day 14).

\section{Combination of growth factors with $\mathrm{OM}$}

As osteogenic differentiation was detected mostly with $\mathrm{OM}$, in the second part of the study growth factors were added to OM to determine whether greater osteo-induction could be achieved by their combination. The viability (Fig. 2 and 3 ) and cell number (Fig. 4b) of OM + growth factors were comparable to that of plain OM, although slightly higher than with $\mathrm{MM}+$ growth factors. In BioRestore the inhibitory effect of BMP-7 on cell number could be detected even when combined with $\mathrm{OM}$, but the difference was not significant to other groups.

Overall, combining growth factors with OM did not result in enhanced ALP activity or collagen production when compared to plain OM. However, in ALP activity, 
the negative effect detected by BMP-7 (Fig. 5a) was rescued when combined with $\mathrm{OM}$ (Fig. 5b); in some donor cells OM + BMP-7 increased ALP activity on day 7 in BioRestore and on day 14 in BoneCeramic, although the difference to plain OM was not significant.

When comparing the effects of $\mathrm{OM}+$ growth factors between the two biomaterials, the results were comparable to those obtained with $\mathrm{MM}+$ growth factors; BioRestore stimulated higher cell number than BoneCeramic, whereas BoneCeramic induced higher ALP activity and collagen production.

\section{Discussion}

Every year, over 2 million bone graft operations are carried-out world-wide (Giannoudis et al., 2005). Due to the limitations of the traditional bone-grafting, alternative approaches such as tissue engineering are emerging in order to meet the increasing need for bone substitutes (Betz, 2002). To date, much reliance has been put on the osteo-inductive effect of BMPs (Garrison et al., 2007; Clokie and Sandor, 2008; Mesimaki et al., 2009). However, the cost, safety and effectiveness of growth factors have been the subject of controversy lately (Alarmo et al., 2009; Garrison et al., 2010; Zuk et al., 2011). Due to the several risks and disadvantages related to the use of growth factors, we studied OM as an alternative method to enhance osteogenic differentiation of hASCs. OM containing AsA2-P, Dex and $\beta$-GP is a cost-effective osteo-inducer of hASCs in vitro as well as in vivo. In several in vivo studies, the osteogenic commitment of ASCs has been enhanced by $\mathrm{OM}$ during the in vitro culture prior to implantation (Cui et al., 2007; Di Bella et al., 2008; Bohnenblust et al., 2009; Schubert et al., 2011). For clinical bone tissue engineering it is critical to reduce the total time required to regenerate functional bone tissue. The pre-implantation expansion of hASCs takes several days to weeks, and bone formation after implantation of the construct takes from several weeks to months. In this respect, induction by OM would be a highly cost-effective way to enhance both osteogenic differentiation and proliferation of hASCs during the in vitro culture preceding implantation of the construct. Although the feasibility of OM-induction has been illustrated in several in vivo studies, the effect of OM has not been systematically compared to BMP-2, BMP-7 and VEGF in vitro.

Consequently, the current study demonstrated significantly greater osteogenic differentiation of hASCs by OM over BMP-2, BMP-7 and VEGF treatment in 3D culture, when the growth factors were added to MM. In fact, $\mathrm{MM}+\mathrm{BMP}-2$ or MM + VEGF treatment did not enhance the osteogenic differentiation of hASC more than $\mathrm{MM}$ alone with either biomaterial. In addition, it was discovered that BMP-7 significantly decreases proliferation and ALP activity of hASCs, an adverse effect that was detected consistently with both biomaterials. As osteogenic differentiation was detected solely with $\mathrm{OM}$, in the second part of the study we tested whether OM could sensitise hASCs to growth factors in order to yield greater osteoinduction. However, the combination of BMP-2, BMP-7 or
VEGF with OM resulted in similar level of osteo-induction to $\mathrm{OM}$ alone, suggesting that $\mathrm{OM}$ induction is sufficient, and that differentiating hASCs may not respond to growth factor stimulation. Interestingly, the inhibitory effect of BMP-7 was rescued when BMP-7 was combined with OM. Hence, OM showed superiority over BMP-2, BMP-7 and VEGF added to MM, and these growth factors added to $\mathrm{OM}$ hold no advantage over plain OM induction in vitro.

Some studies have suggested that exogenously added BMP-2 (Knippenberg et al., 2006; Song et al., 2011), BMP-7 (Al-Salleeh et al., 2008) and VEGF (Behr et al., 2011) could have an osteo-inductive effect on ASCs, but in the current study these growth factors did not enhance osteogenic differentiation of hASC more than MM with either biomaterial. Out of these three growth factors, BMP2 is the most studied with ASCs (Knippenberg et al., 2006; E et al., 2010; Song et al., 2011; Zuk et al., 2011; Mehrkens et al., 2012; Overman et al., 2012). Although BMP-2 concentrations from 50 to $100 \mathrm{ng} / \mathrm{mL}$ have successfully induced osteogenic differentiation of ASCs in some studies (Song et al., 2011; Knippenberg et al., 2006), Zuk and co-workers found no effect with doses in the range of 10$100 \mathrm{ng} / \mathrm{mL}$ (Zuk et al., 2011). Similar to the findings of the present study and those reported by Zuk and co-workers, a recent study showed no effect by BMP-2 with $50 \mathrm{ng} /$ $\mathrm{mL}$ (Mehrkens et al., 2012). However, Mehrkens and coworkers suggested that a 10 times higher concentration, $500 \mathrm{ng} / \mathrm{mL}$, is able to stimulate osteogenic differentiation of hASCs in vitro (Mehrkens et al., 2012). In turn, this is in contrast to two studies, where a short, only $15 \mathrm{~min}$ treatment with $10 \mathrm{ng} / \mathrm{mL}$ BMP-2 was able to support osteoinduction of ASCs for 14-21 days (Knippenberg et al., 2006; Overman et al., 2012). Hence, there is no consensus on the effect of BMP-2 on osteo-induction of ASCs, and further systematic in vitro and in vivo studies are required.

Several factors may explain the great variation in the outcomes of BMP-2 studies, including use of animalderived ASCs (Knippenberg et al., 2006; E et al., 2010), differential effects of 3D biomaterials (E et al., 2010; Overman et al., 2012) to 2D culture, and the use of various cell densities and culture media. Nevertheless, various explanations have been suggested for the failure of BMP induction in ASCs and bone marrow stromal cells (BMSCs), including up-regulation of BMP antagonists such as noggin and gremlin (Pereira et al., 2000; Diefenderfer et al., 2003; Sutherland et al., 2004; Zuk et al., 2011). On the other hand, the problem may originate from an insufficient activation of downstream signalling related to phosphorylation and nuclear translocation of certain Smads, the intracellular target proteins of e.g. BMP-2 signalling, as proposed by Zuk and co-workers (Zuk et al., 2011). It is obvious that several aspects of cell signalling including timing, dosage, and complex interplay between different effectors and inhibitors need further elucidation to master the effect of growth factors.

The expanding literature on in vivo experiments conducted with ASCs suggests two critical requirements for successful bone formation; firstly, the osteogenic commitment of ASCs, and secondly, the presence of a mineral component in a scaffold (Scherberich et al., 2010). The biomaterials used in the current study were 
chosen because they represent prospective candidates for hASC-based bone tissue engineering approaches. As such, osteoconductivity and ability to heal bony defects has been reported in clinical and in vivo studies for both BioRestore (Moimas et al., 2006; Clozza et al., 2012a; Clozza et al., 2012b) and BoneCeramic (Jensen et al., 2007; Jensen et al., 2009; Frenken et al., 2010; Rokn et al., 2011). Although capable of orthotopic bone formation, BoneCeramic failed to form ectopic bone together with BMSCs in subcutaneous rodent models (Zimmermann et al., 2011; Mrozik et al., 2012) indicating a need for enhanced osteo-induction. Recently, a similar biomaterial to BoneCeramic, except in a porous block format, was shown to increase bone formation in segmental femoral defects significantly more when seeded with hASCs than without cells (Choi et al., 2011). In a clinical study of 13 patients, BioRestore alone was able to induce formation of woven bone in tooth extraction sockets, although no mature lamellar bone was detected within a 6 months healing period (Clozza et al., 2012b). However, the bone formation capacity of BioRestore could be enhanced significantly by hASC transplantation in the future. Promising in vitro results have been reported previously for culturing hASCs in BioRestore scaffolds under control conditions (Haimi et al., 2009b). Previous in vitro studies with BoneCeramic have been conducted with fibroblasts (Kauschke et al., 2006), periodontal ligament fibroblasts (Mrozik et al., 2012) and BMSCs (Mrozik et al., 2012), but this is the first study to report hASC response on BoneCeramic and BioRestore when combined with osteo-induction by growth factors or OM.

The aim of the current study was to compare the efficiency of OM and growth factors for the osteo-induction of hASCs using two clinically prospective biomaterial carriers. Importantly, our findings indicate that the $3 \mathrm{D}$ biomaterial plays a notable role in hASC behaviour. The most significant difference between the 3D hASC-carriers, BioRestore and BoneCeramic, was detected in their ability to stimulate collagen production by hASCs. BoneCeramic induced a significantly larger amount of collagenous matrix than BioRestore under control conditions, and the effect was further enhanced with OM. Although different types of collagens are present in several tissues, the onset of osteoblastic differentiation is strongly related to the formation of organic matrix, mainly consisting of collagen type I, which will be subsequently mineralised - a process that is in turn facilitated by the accumulation of phosphate as a function of ALP enzyme. The differential behaviour of hASCs may be dependent on differences between the chemistry, topography, or 3D structure of the biomaterials.

The other major difference between the biomaterials was detected in their capacity to support cell proliferation, as BioRestore resulted in a significantly higher hASC number than BoneCeramic, an effect likely related to the 3D structure of the biomaterials. The fibre structure of BioRestore provides large surface area and allows the cells to spread more easily throughout the scaffold, whereas the granular format in BoneCeramic provides less contact area between the granules, hindering the spreading of the cells. This hypothesis was further supported by the viability assay, as some BoneCeramic granules were fully populated by hASCs whereas other granules in the same well had no or very few cells. Based on these results, a larger initial cell seeding concentration would be recommended for BoneCeramic when considering clinical approaches to guarantee sufficient and evenly distributed cell population over the biomaterial. Although the comparison of these two biomaterials is challenging, due to the major differences in their 3D structures, based on our results both carriers represent viable alternatives for hASC-based bone tissue engineering as such, although combined stimulation with $\mathrm{OM}$ is suggested for efficient osteo-induction.

Based on the valuable in vitro findings of the present study, a corresponding in vivo study to demonstrate the utility of OM over growth factors has been planned. In order to reduce the number of animal experiments to be performed, it was critical to evaluate the hASCs response to growth factors and $\mathrm{OM}$ in vitro. For example, based on our results, there is no point in testing growth factors with $\mathrm{OM}$, because there was no extra benefit from $\mathrm{OM}+$ growth factors in comparison to $\mathrm{OM}$ alone. Therefore, it is not necessary to test all the groups used in the current study in vivo. However, in the future in vivo study, effectiveness of OM over growth factors in MM should be demonstrated.

\section{Conclusions}

To conclude, this is the first study to demonstrate that $\mathrm{OM}$ enhances hASC differentiation towards boneforming cells in $3 \mathrm{D}$ culture significantly more than the traditionally used growth factors BMP-2, BMP-7 and VEGF. Both biomaterials tested in this study, BioRestore and BoneCeramic, supported the hASC viability and proliferation during 14 days of culture. The most significant osteogenic differentiation of hASCs was achieved by BoneCeramic combined with OM. In contrast, combining growth factors with either biomaterial did not increase osteogenic differentiation or proliferation when compared to MM. Moreover, BMP-7 consistently inhibited proliferation and osteogenic differentiation of hASCs in $3 \mathrm{D}$ culture. Combining OM with BMP-7 eliminated the adverse effect of BMP-7. Otherwise, there was no significant benefit from adding growth factors to OM. Our results indicate that instead of BMP-2, BMP-7 or VEGF, OM should be used to obtain successful osteogenic commitment of hASCs in vitro.

\section{Acknowledgements}

The authors thank Ms. Anna-Maija Honkala, Ms. Miia Juntunen, Ms. Sari Kalliokoski, and Ms. Minna Salomäki for technical assistance with the hASCs. We are grateful to Straumann AG, especially to PhD Aart Molenberg and PhD Martin Schuler, for the delivery of Straumann ${ }^{\circledR}$ BoneCeramic. In addition, the authors thank Dr. Hannu Kuokkanen for the delivery of fat samples for stem cell isolation, $\mathrm{PhD}$ Bettina Mannerström for flow cytometric analysis, and MSc Taru Karhula for SEM images. This study has been financially supported by the Competitive Research Funding of Tampere University Hospital (grants 9L057, 9K117, 9L100, 9M058 and 9J014), the Finnish 
Funding Agency for Technology and Innovation (TEKES), Academy of Finland, and The Science Centre of Tampere City.

\section{References}

Al-Salleeh F, Beatty MW, Reinhardt RA, Petro TM, Crouch L (2008) Human osteogenic protein-1 induces osteogenic differentiation of adipose-derived stem cells harvested from mice. Arch Oral Biol 53: 928-936.

Alarmo EL, Parssinen J, Ketolainen JM, Savinainen K, Karhu R, Kallioniemi A (2009) BMP7 influences proliferation, migration, and invasion of breast cancer cells. Cancer Lett 275: 35-43.

Axelrad TW, Steen B, Lowenberg DW, Creevy WR, Einhorn TA (2008) Heterotopic ossification after the use of commercially available recombinant human bone morphogenetic proteins in four patients. J Bone Joint Surg Br 90: 1617-1622.

Barr T, McNamara AJ, Sandor GK, Clokie CM, Peel SA (2010) Comparison of the osteoinductivity of bioimplants containing recombinant human bone morphogenetic proteins 2 (Infuse) and 7 (OP-1). Oral Surg Oral Med Oral Pathol Oral Radiol Endod 109: 531-540.

Behr B, Tang C, Germann G, Longaker MT, Quarto N (2011) Locally applied vascular endothelial growth factor a increases the osteogenic healing capacity of human adipose-derived stem cells by promoting osteogenic and endothelial differentiation. Stem Cells 29: 286-296.

Betz RR (2002) Limitations of autograft and allograft: new synthetic solutions. Orthopedics 25: 561-570.

Bohnenblust ME, Steigelman MB, Wang Q, Walker JA, Wang HT (2009) An experimental design to study adipocyte stem cells for reconstruction of calvarial defects. J Craniofac Surg 20: 340-346.

Choi HJ, Kim JM, Kwon E, Che JH, Lee JI, Cho SR, Kang SK, Ra JC, Kang BC (2011) Establishment of efficacy and safety assessment of human adipose tissuederived mesenchymal stem cells (hATMSCs) in a nude rat femoral segmental defect model. J Korean Med Sci 26: 482-491.

Choi YS, Vincent LG, Lee AR, Dobke MK, Engler AJ (2012) Mechanical derivation of functional myotubes from adipose-derived stem cells. Biomaterials 33: 2482-2491.

Clokie CM, Sandor GK (2008) Reconstruction of 10 major mandibular defects using bioimplants containing BMP-7. J Can Dent Assoc 74: 67-72.

Clozza E, Biasotto M, Cavalli F, Moimas L, Di Lenarda R (2012a) Three-dimensional evaluation of bone changes following ridge preservation procedures. Int J Oral Maxillofac Implants 27: 770-775.

Clozza E, Pea M, Cavalli F, Moimas L, Di Lenarda R, Biasotto M (2012b) Healing of fresh extraction sockets filled with bioactive glass particles: histological findings in humans. Clin Implant Dent Relat Res, in press.

Cowan CM, Shi YY, Aalami OO, Chou YF, Mari C, Thomas R, Quarto N, Contag CH, Wu B, Longaker MT (2004) Adipose-derived adult stromal cells heal criticalsize mouse calvarial defects. Nat Biotechnol 22: 560-567.
Cui L, Liu B, Liu G, Zhang W, Cen L, Sun J, Yin S, Liu W, Cao Y (2007) Repair of cranial bone defects with adipose derived stem cells and coral scaffold in a canine model. Biomaterials 28: 5477-5486.

D’Alimonte I, Nargi E, Mastrangelo F, Falco G, Lanuti P, Marchisio M, Miscia S, Robuffo I, Capogreco M, Buccella S, Caputi S, Caciagli F, Tete S, Ciccarelli R (2011) Vascular endothelial growth factor enhances in vitro proliferation and osteogenic differentiation of human dental pulp stem cells. J Biol Regul Homeost Agents 25: 57-69.

De Girolamo L, Sartori MF, Albisetti W, Brini AT (2007) Osteogenic differentiation of human adiposederived stem cells: comparison of two different inductive media. J Tissue Eng Regen Med 1: 154-157.

Di Bella C, Farlie P, Penington AJ (2008) Bone regeneration in a rabbit critical-sized skull defect using autologous adipose-derived cells. Tissue Eng Part A 14: 483-490.

Diefenderfer DL, Osyczka AM, Garino JP, Leboy PS (2003) Regulation of BMP-induced transcription in cultured human bone marrow stromal cells. J Bone Joint Surg Am 85-A Suppl 3: 19-28.

Dominici M, Le Blanc K, Mueller I, Slaper-Cortenbach I, Marini F, Krause D, Deans R, Keating A, Prockop D, Horwitz E (2006) Minimal criteria for defining multipotent mesenchymal stromal cells. The International Society for Cellular Therapy position statement. Cytotherapy 8: 315317.

Dudas JR, Marra KG, Cooper GM, Penascino VM, Mooney MP, Jiang S, Rubin JP, Losee JE (2006) The osteogenic potential of adipose-derived stem cells for the repair of rabbit calvarial defects. Ann Plast Surg 56: 543548.

E LL, Xu LL, Wu X, Wang DS, Lv Y, Wang JZ, Liu HC (2010) The interactions between rat-adipose-derived stromal cells, recombinant human bone morphogenetic protein-2, and beta-tricalcium phosphate play an important role in bone tissue engineering. Tissue Eng Part A 16: 2927-2940.

Frenken JW, Bouwman WF, Bravenboer N, Zijderveld SA, Schulten EA, ten Bruggenkate CM (2010) The use of Straumann Bone Ceramic in a maxillary sinus floor elevation procedure: a clinical, radiological, histological and histomorphometric evaluation with a 6-month healing period. Clin Oral Implants Res 21: 201-208.

Garrido CA, Lobo SE, Turibio FM, Legeros RZ (2011) Biphasic calcium phosphate bioceramics for orthopaedic reconstructions: clinical outcomes. Int J Biomater 2011: 129727.

Garrison KR, Donell S, Ryder J, Shemilt I, Mugford M, Harvey I, Song F (2007) Clinical effectiveness and cost-effectiveness of bone morphogenetic proteins in the non-healing of fractures and spinal fusion: a systematic review. Health Technol Assess 11: 1-150, iii-iv.

Garrison KR, Shemilt I, Donell S, Ryder JJ, Mugford M, Harvey I, Song F, Alt V (2010) Bone morphogenetic protein (BMP) for fracture healing in adults. Cochrane Database Syst Rev 6: CD006950. 
Ghanaati S, Barbeck M, Detsch R, Deisinger U, Hilbig U, Rausch V, Sader R, Unger RE, Ziegler G, Kirkpatrick CJ (2012) The chemical composition of synthetic bone substitutes influences tissue reactions in vivo: histological and histomorphometrical analysis of the cellular inflammatory response to hydroxyapatite, beta-tricalcium phosphate and biphasic calcium phosphate ceramics. Biomed Mater 7: 015005.

Giannoudis PV, Dinopoulos H, Tsiridis E (2005) Bone substitutes: an update. Injury 36 Suppl 3: S20-27.

Giannoudis PV, Kanakaris NK, Einhorn TA (2007) Interaction of bone morphogenetic proteins with cells of the osteoclast lineage: review of the existing evidence. Osteoporos Int 18: 1565-1581.

Giusta MS, Andrade H, Santos AV, Castanheira P, Lamana L, Pimenta AM, Goes AM (2010) Proteomic analysis of human mesenchymal stromal cells derived from adipose tissue undergoing osteoblast differentiation. Cytotherapy 12: 478-490.

Haimi S, Gorianc G, Moimas L, Lindroos B, Huhtala H, Raty S, Kuokkanen H, Sandor GK, Schmid C, Miettinen S, Suuronen R (2009a) Characterization of zinc-releasing three-dimensional bioactive glass scaffolds and their effect on human adipose stem cell proliferation and osteogenic differentiation. Acta Biomater 5: 3122-3131.

Haimi S, Moimas L, Pirhonen E, Lindroos B, Huhtala H, Raty S, Kuokkanen H, Sandor GK, Miettinen S, Suuronen R (2009b) Calcium phosphate surface treatment of bioactive glass causes a delay in early osteogenic differentiation of adipose stem cells. J Biomed Mater Res A 91: 540-547.

Hattori H, Masuoka K, Sato M, Ishihara M, Asazuma T, Takase B, Kikuchi M, Nemoto K (2006) Bone formation using human adipose tissue-derived stromal cells and a biodegradable scaffold. J Biomed Mater Res B Appl Biomater 76: 230-239.

Hench LL (1998) Biomaterials: a forecast for the future. Biomaterials 19: 1419-1423.

Hicok KC, Du Laney TV, Zhou YS, Halvorsen YD, Hitt DC, Cooper LF, Gimble JM (2004) Human adipose-derived adult stem cells produce osteoid in vivo. Tissue Eng 10: 371-380.

Jensen SS, Bornstein MM, Dard M, Bosshardt DD, Buser D (2009) Comparative study of biphasic calcium phosphates with different HA/TCP ratios in mandibular bone defects. A long-term histomorphometric study in minipigs. J Biomed Mater Res B Appl Biomater 90: 171181.

Jensen SS, Yeo A, Dard M, Hunziker E, Schenk R, Buser D (2007) Evaluation of a novel biphasic calcium phosphate in standardized bone defects: a histologic and histomorphometric study in the mandibles of minipigs. Clin Oral Implants Res 18: 752-760.

Kauschke E, Rumpel E, Fanghanel J, Bayerlein T, Gedrange T, Proff P (2006) The in vitro viability and growth of fibroblasts cultured in the presence of different bone grafting materials (NanoBone and Straumann Bone Ceramic). Folia Morphol (Warsz) 65: 37-42.

Kim H, Kim HW, Suh H (2003) Sustained release of ascorbate-2-phosphate and dexamethasone from porous PLGA scaffolds for bone tissue engineering using mesenchymal stem cells. Biomaterials 24: 4671-4679.

Kim H, Suh H, Jo SA, Kim HW, Lee JM, Kim EH, Reinwald Y, Park SH, Min BH, Jo I (2005) In vivo bone formation by human marrow stromal cells in biodegradable scaffolds that release dexamethasone and ascorbate-2phosphate. Biochem Biophys Res Commun 332: 10531060.

Knippenberg M, Helder MN, Zandieh Doulabi B, Wuisman PI, Klein-Nulend J (2006) Osteogenesis versus chondrogenesis by BMP-2 and BMP-7 in adipose stem cells. Biochem Biophys Res Commun 342: 902-908.

Kokubo T, Kim HM, Kawashita M (2003) Novel bioactive materials with different mechanical properties. Biomaterials 24: 2161-2175.

Lindfors NC, Koski I, Heikkila JT, Mattila K, Aho AJ (2010) A prospective randomized 14-year follow-up study of bioactive glass and autogenous bone as bone graft substitutes in benign bone tumors. J Biomed Mater Res B Appl Biomater 94: 157-164.

Lindroos B, Aho KL, Kuokkanen H, Raty S, Huhtala H, Lemponen R, Yli-Harja O, Suuronen R, Miettinen S (2010) Differential gene expression in adipose stem cells cultured in allogeneic human serum versus fetal bovine serum. Tissue Eng Part A 16: 2281-2294.

McCullen SD, McQuilling JP, Grossfeld RM, Lubischer JL, Clarke LI, Loboa EG (2010) Application of low-frequency alternating current electric fields via interdigitated electrodes: effects on cellular viability, cytoplasmic calcium, and osteogenic differentiation of human adipose-derived stem cells. Tissue Eng Part C Methods 16: 1377-1386.

McIntosh K, Zvonic S, Garrett S, Mitchell JB, Floyd ZE, Hammill L, Kloster A, Di Halvorsen Y, Ting JP, Storms RW, Goh B, Kilroy G, Wu X, Gimble JM (2006) The immunogenicity of human adipose-derived cells: temporal changes in vitro. Stem Cells 24: 1246-1253.

Mehrkens A, Saxer F, Güven S, Hoffmann W, Müller AM, Jakob M, Weber FE, Martin I, Scherberich A (2012) Intraoperative engineering of osteogenic grafts combining freshly harvested, human adipose-derived cells and physiological doses of bone morphogenetic protein-2. Eur Cell Mater 24: 308-319.

Mesimaki K, Lindroos B, Tornwall J, Mauno J, Lindqvist C, Kontio R, Miettinen S, Suuronen R (2009) Novel maxillary reconstruction with ectopic bone formation by GMP adipose stem cells. Int J Oral Maxillofac Surg 38: 201-209.

Moimas L, Biasotto M, Di Lenarda R, Olivo A, Schmid C (2006) Rabbit pilot study on the resorbability of threedimensional bioactive glass fibre scaffolds. Acta Biomater 2: 191-199.

Mrozik KM, Gronthos S, Menicanin D, Marino V, Bartold PM (2012) Effect of coating Straumann(R) Bone Ceramic with Emdogain on mesenchymal stromal cell hard tissue formation. Clin Oral Investig 16: 867-878.

Ogawa R, Mizuno H, Watanabe A, Migita M, Shimada T, Hyakusoku H (2004) Osteogenic and chondrogenic differentiation by adipose-derived stem cells harvested from GFP transgenic mice. Biochem Biophys Res Commun 313: 871-877. 
Overman JR, Farré-Guasch E, Helder MN, Ten Bruggenkate CM, Schulten EA, Klein-Nulend J (2012) Short (15 minutes) BMP-2 treatment stimulates osteogenic differentiation of human adipose stem cells seeded on calcium phosphate scaffolds in vitro. Tissue Eng Part A, in press. doi:10.1089/ten.tea.2012.0133.

Park A, Hogan MV, Kesturu GS, James R, Balian G, Chhabra AB (2010) Adipose-derived mesenchymal stem cells treated with growth differentiation factor-5 express tendon-specific markers. Tissue Eng Part A 16: 2941-2951.

Peltola M, Aitasalo K, Suonpaa J, Varpula M, YliUrpo A (2006) Bioactive glass S53P4 in frontal sinus obliteration: a long-term clinical experience. Head Neck 28: 834-841.

Peltola M, Kinnunen I, Aitasalo K (2008) Reconstruction of orbital wall defects with bioactive glass plates. J Oral Maxillofac Surg 66: 639-646.

Pereira RC, Economides AN, Canalis E (2000) Bone morphogenetic proteins induce gremlin, a protein that limits their activity in osteoblasts. Endocrinology 141: 4558-4563.

Rada T, Reis RL, Gomes ME (2011) Distinct stem cells subpopulations isolated from human adipose tissue exhibit different chondrogenic and osteogenic differentiation potential. Stem Cell Rev 7: 64-76.

Rokn AR, Khodadoostan MA, Reza Rasouli Ghahroudi AA, Motahhary P, Kharrazi Fard MJ, Bruyn HD, Afzalifar R, Soolar E, Soolari A (2011) Bone formation with two types of grafting materials: a histologic and histomorphometric study. Open Dent J 5: 96-104.

Roldan JC, Detsch R, Schaefer S, Chang E, Kelantan M, Waiss W, Reichert TE, Gurtner GC, Deisinger U (2010) Bone formation and degradation of a highly porous biphasic calcium phosphate ceramic in presence of BMP-7, VEGF and mesenchymal stem cells in an ectopic mouse model. J Craniomaxillofac Surg 38: 423-430.

Samartzis D, Khanna N, Shen FH, An HS (2005) Update on bone morphogenetic proteins and their application in spine surgery. J Am Coll Surg 200: 236-248.

Scherberich A, Muller AM, Schafer DJ, Banfi A, Martin I (2010) Adipose tissue-derived progenitors for engineering osteogenic and vasculogenic grafts. J Cell Physiol 225: 348-353.

Schubert T, Xhema D, Veriter S, Schubert M, Behets C, Delloye C, Gianello P, Dufrane D (2011) The enhanced performance of bone allografts using osteogenicdifferentiated adipose-derived mesenchymal stem cells. Biomaterials 32: 8880-8891.

Shen B, Wei A, Whittaker S, Williams LA, Tao H, Ma DD, Diwan AD (2010) The role of BMP-7 in chondrogenic and osteogenic differentiation of human bone marrow multipotent mesenchymal stromal cells in vitro. J Cell Biochem 109: 406-416.

Song I, Kim BS, Kim CS, Im GI (2011) Effects of BMP-2 and vitamin D3 on the osteogenic differentiation of adipose stem cells. Biochem Biophys Res Commun 408: 126-131.

Sutherland MK, Geoghegan JC, Yu C, Winkler DG, Latham JA (2004) Unique regulation of SOST, the sclerosteosis gene, by BMPs and steroid hormones in human osteoblasts. Bone 35: 448-454.
Thesleff T, Lehtimaki K, Niskakangas T, Mannerstrom B, Miettinen S, Suuronen R, Ohman J (2011) Cranioplasty with adipose-derived stem cells and biomaterial. A novel method for cranial reconstruction. Neurosurgery 68: 15351540 .

Tirkkonen L, Halonen H, Hyttinen J, Kuokkanen H, Sievanen H, Koivisto AM, Mannerstrom B, Sandor GK, Suuronen R, Miettinen S, Haimi S (2011) The effects of vibration loading on adipose stem cell number, viability and differentiation towards bone-forming cells. J R Soc Interface 8: 1736-1747.

Wysocki RW, Cohen MS (2007) Ectopic ossification of the triceps muscle after application of bone morphogenetic protein-7 to the distal humerus for recalcitrant nonunion: a case report. J Hand Surg Am 32: 647-650.

Xynos ID, Hukkanen MV, Batten JJ, Buttery LD, Hench LL, Polak JM (2000) Bioglass 45S5 stimulates osteoblast turnover and enhances bone formation In vitro: implications and applications for bone tissue engineering. Calcif Tissue Int 67: 321-329.

Yoon E, Dhar S, Chun DE, Gharibjanian NA, Evans GR (2007) In vivo osteogenic potential of human adiposederived stem cells/poly lactide-co-glycolic acid constructs for bone regeneration in a rat critical-sized calvarial defect model. Tissue Eng 13: 619-627.

Zimmermann CE, Gierloff M, Hedderich J, Acil Y, Wiltfang J, Terheyden H (2011) Survival of transplanted rat bone marrow-derived osteogenic stem cells in vivo. Tissue Eng Part A 17: 1147-1156.

Zuk P, Chou YF, Mussano F, Benhaim P, Wu BM (2011) Adipose-derived stem cells and BMP2: part 2. BMP2 may not influence the osteogenic fate of human adipose-derived stem cells. Connect Tissue Res 52: 119-132.

Zuk PA, Zhu M, Ashjian P, De Ugarte DA, Huang JI, Mizuno H, Alfonso ZC, Fraser JK, Benhaim P, Hedrick $\mathrm{MH}$ (2002) Human adipose tissue is a source of multipotent stem cells. Mol Biol Cell 13: 4279-4295.

Zuk PA, Zhu M, Mizuno H, Huang J, Futrell JW, Katz AJ, Benhaim P, Lorenz HP, Hedrick MH (2001) Multilineage cells from human adipose tissue: implications for cell-based therapies. Tissue Eng 7: 211-228.

\section{Discussion with Reviewers}

Reviewer I: Fig. 6 compares collagen content among different groups, what is the collagen normalised to among different groups?

Authors: Fig. 6 shows the absolute values obtained as absorbance; hence the results have not been normalised. Absorbance is directly proportional to the amount of collagen in the samples; therefore, a reliable comparison among different groups can be obtained using absolute values. Unfortunately, with the collagen assay, it was not possible to determine cell number from the same samples.

Reviewer I: Authors need to provide in vivo data to demonstrate that ADSC preconditioned in osteogenic medium are better at forming bone in vivo than ADSCs exposed to BMP-2 or any other growth factors. Results from these studies would enhance the data being reported. 
Authors: The authors agree that in vivo study is important to further demonstrate the efficiency of OM over BMP2, BMP-7 and VEGF. However, the authors feel that the present study in its current form provides valuable information on the effects of BMP-2, BMP-7, VEGF and $\mathrm{OM}$ on hASC proliferation and osteogenic differentiation in 3D scaffolds, and behaviour of hASCs in two clinically relevant biomaterials. These valuable findings can be utilised to better plan the corresponding in vivo study. In order to reduce the number of animal experiments to be performed, it is critical to evaluate the hASCs response to growth factors and OM in vitro. For example, based on our results, there is no point in testing growth factors with $\mathrm{OM}$, because there was no extra benefit from $\mathrm{OM}+$ growth factors in comparison to $\mathrm{OM}$ alone. Therefore, it is not necessary to test all of the groups used in the current study in vivo. However, in the future in vivo study, effectiveness of OM over growth factors in MM should be demonstrated. It is clear that systematic in vitro data is of fundamental importance before it is reasonable to conduct in vivo studies. The in vitro results also facilitate the correct interpretation of the in vivo results.

Reviewer I: The present report concludes that osteogenic medium is superior in enhancing adipose derived stem cells differentiation toward osteogenic lineage than bone morphogenetic proteins. Although, the data reported is valid, use of osteogenic medium to assess osteogenic differentiation is an established protocol. There are controversies regarding response of adipose derived stem cells to BMP-2 to induce osteoblasts differentiation; some reports have shown positive response others have shown reduced response. The findings reported in this manuscript thus confirm original observations. Please comment.
Authors: We would like to note that the OM used in our study is not that traditionally used, but specifically optimised for hASCs. The modified OM with low Dex $(5 \mathrm{nM})$ and high AsA2-P $(250 \mu \mathrm{M})$ concentration used in this study may have contributed to the superior effect of the OM over the tested growth factors. Because the traditional OM with high Dex (100 nM) and low AsA2-P $(50 \mu \mathrm{M})$ was originally developed based on studies with BMSCs (Jaiswal et al., 1997, additional reference), it has been reported that OM with lower Dex and higher AsA2-P is more optimal for ASCs (De Girolamo et al., 2007, text reference; Kyllönen et al., unpublished results). However, our study, where the efficiency of the modified OM over the traditional OM has been reported, is under submission (Kyllönen et al., unpublished results). This modified OM has been used successfully for the efficient osteo-induction of hASCs previously (Tirkkonen et al., 2011, text reference). Although several studies have been conducted with BMP-2, there is still no consensus on the effect of BMP-2 on osteo-induction of hASCs. In addition, the effects of BMP-7 and VEGF have been even less reported on hASCs than BMP-2. Furthermore, in the present study, these growth factors were systematically compared in control medium and OM.

\section{Additional Reference}

Jaiswal N, Haynesworth SE, Caplan AI, Bruder SP (1997) Osteogenic differentiation of purified, cultureexpanded human mesenchymal cells in vitro. J Cell Biochem 64: 295-312. 